\title{
Diffusion Characteristics of Toluene into Natural Rubber/Linear Low Density Polyethylene Blends
}

\author{
Henry C. Obasi, Okoro Ogbobe, and Isaac O. Igwe \\ Department of Polymer and Textile Engineering, Federal University of Technology, Owerri, P.M.B. 1526 Imo State, Nigeria \\ Correspondence should be addressed to Isaac O. Igwe, izikigwe@yahoo.com
}

Received 24 January 2009; Revised 14 July 2009; Accepted 6 December 2009

Recommended by Jan-Chan Huang

\begin{abstract}
The sorption and diffusion of toluene through blends of natural rubber (NR) and linear low density polyethylene (LLDPE) of varying compositions were studied at 35,55 , and $65^{\circ} \mathrm{C}$ by conventional weight-gain experiments. The effects of blend ratio on the diffusion, sorption, and permeation coefficients were determined. The sorption data were used to estimate the activation energies of diffusion and permeation, parameters which were found to show a decrease when the amount of NR or LLDPE was increased. The transport of toluene through most of the blends was anomalous, althouh at $35^{\circ} \mathrm{C}$, the transport of toluene through the $60 / 40$ blend was Fickian and at $35^{\circ} \mathrm{C}$, pseudo-Fickian. The enthalpy of sorption of toluene obtained is positive and suggests a Henry's type sorption.
\end{abstract}

Copyright ( 2009 Henry C. Obasi et al. This is an open access article distributed under the Creative Commons Attribution License, which permits unrestricted use, distribution, and reproduction in any medium, provided the original work is properly cited.

\section{Introduction}

The past decades have witnessed increasing importance of polymer blending since it is possible to obtain desirable properties by simple blending of polymers. Generally, the blending of two or more polymers makes it possible to obtain a material with properties superior to those of individual constituents and thus, be used in application areas that are not possible with either of the constituent polymers in the blend. The desired property improvements obtainable through polymer blending include impact strength, heat distortion temperature, flame retardancy, permeability characteristics, and processibility, in addition to cost reduction [1]. The physical properties of polymer blends are controlled generally by many factors such as the nature of polymer [2], blend composition [3-5], and interfacial adhesion [612]. The blending of natural rubber not only leads to a reduction in the cost of the compound, it also makes it easier to fabricate complex shapes during production $[13,14]$.

The presence of solvents in polymers or blends assumes significance since most polymers after swelling in the solvent show a reduction in its properties. Therefore, polymers for commercial applications should be chemically resistant and retain their mechanical strength and dimensional stability on contact with solvents. Thus, the basic transport phenomenon plays a prominent role in many industrial and engineering applications of polymers [15-20]. It has been pointed out that the study of diffusion, sorption, and permeation in blend structure provides valuable means for additional characterization of polymer blends [21].

Natural rubber, an elastomer has been extensively studied because of its wide usage in tyre production. Since no elastomer has all the characteristics required in many application areas, elastomers are commonly blended to improve their performance. Blends of natural rubber have been reported to be compatible with desirable mechanical properties [22-26]. Excellent reports exist in the literature on the diffusion and sorption processes in elastomer and their various blends. Thus, transport studies have been conducted on natural rubber/epoxidized natural rubber [27], natural rubber/polystyrene [28], nitrile rubber/polypropylene [29], and ethylene-propylene rubber/nylon blends [30].

In the present paper, blends of natural rubber and linear low density polyethylene have been prepared. The diffusion of toluene, an aromatic solvent, through the blends has been investigated and the mechanism of sorption through the blends was determined. The diffusion, sorption, and permeation coefficients were calculated. Also, the effects of blend composition and temperature were studied. 
The analysis of diffusion of toluene through natural rubber/linear low density polyethylene blends has not been reported in the scientific literature to our knowledge. However, the development of natural rubber and ultra-low density polyethylene blends were reported by Tanrattanakul and Udomkichdecha [31] who determined the physical and mechanical properties of the blends, and compared the results obtained with those of natural rubber/styrene butadiene rubber.

Similarly, the mechanical properties of filled natural rubber/linear low density polyethylene blends was studied by Ahmad et al. [32]. The swelling index of the rubber blends in toluene for 24 hours at room temperature was determined, and it was found that the swelling index decreased with increasing filler loading.

Toluene, an aromatic solvent generally used in the rubber industry, was chosen as the solvent for this investigation.

\section{Materials and Methods}

2.1. Materials. The linear low density polyethylene used in this study was purchased from a Chemical Store at Aba, Abia State, Nigeria. It has a melt flow index of $2.5 \mathrm{~g} / \mathrm{min}$ and density $0.926 \mathrm{~g} / \mathrm{cm}^{3}$. Natural rubber and other vulcanizing ingredients such as zinc oxide, stearic acid, carbon black (330 HAF), wax, MBT, TMTD, and sulphur were kindly provided by Michelin Company Ltd, Port Harcourt, Nigeria.

2.2. Preparation of Rubber Blends. The formulation used in preparing the rubber blends is given in Table 1. Weighed amounts of the compounding ingredients with the exception of vulcanizing agent and accelerators were first introduced into a Banbury mixer already preset at $145-150^{\circ} \mathrm{C}$ for the mastication of the ingredients, and the rubber blend produced was later transferred to a two-roll mill which converted it from an irregularly shaped mass to suitable sheets. The temperature of the mill was reduced from $170^{\circ} \mathrm{C}$ to $90^{\circ} \mathrm{C}$ before the introduction of the vulcanizing agent and accelerators to prevent premature curing of the compound mix. The rubber blends were calendered and allowed to condition for seven hours after which they were cut into pieces and cured in an autoclave.

2.3. Procedure for Sorption Experiment. Uniform size cut blends were weighed on an electronic balance having an accuracy of $0.001 \mathrm{~g}$. The cut samples were put into sample bottles with covers. $20 \mathrm{~mL}$ of toluene was poured into each of the sample bottles. The bottles were placed in a thermostatically controlled water bath at $35^{\circ} \mathrm{C}$ and were equilibrated for different time intervals. At the expiration of the specified time, the blends were removed from the sample bottles, wiped free of adhering solvent (toluene), and weighed using the electronic balance. The weighing was continued till equilibrium swelling was attained. The experiments were further repeated at 55 and $65^{\circ} \mathrm{C}$. Each weighing was completed in less than 40 seconds, so as to keep the error due to solvent evaporation from the sample surface at a minimum [33].
TABLE 1: Compounding recipe of rubber (parts per 100 parts of rubber by weight).

\begin{tabular}{lccc}
\hline Ingredients & $\begin{array}{c}75 / 25 \\
\text { NR/LLDPE }\end{array}$ & $\begin{array}{c}60 / 40 \\
\text { NR/LLDPE }\end{array}$ & $\begin{array}{c}50 / 50 \\
\text { NR/LLDPE }\end{array}$ \\
\hline NR/LLDPE & 100 & 100 & 100 \\
Zinc oxide & 5 & 5 & 5 \\
Stearic acid & 2 & 2 & 2 \\
Carbon black & & 55 & \\
(330 HAF) & 55 & 4 & 55 \\
Wax & 4 & 0.5 & 4 \\
MBT & 0.5 & 1 & 0.5 \\
TMTD & 1 & 3 & 1 \\
Sulphur & 3 & & 3 \\
\hline
\end{tabular}

MBT: mercaptobenzoyl thiazole;

TMTD: tetramethylthiuram disulphide.

\section{Results and Discussion}

The sorption data of toluene into NR/LLDPE blends at different temperatures $\left(35,55\right.$, and $\left.65^{\circ} \mathrm{C}\right)$ were determined and expressed as the molar percentage uptake $\left(Q_{t}\right)$ of toluene per gram of NR/LLDPE blends. $Q_{t}$ was calculated using (1) [34]

$$
\begin{aligned}
Q_{t}= & \frac{\text { Mass of toluene absorbed }}{\text { Molecular weight of toluene/Initial mass of the blend }} \\
& \times 100 .
\end{aligned}
$$

The molar percentage uptake $\left(Q_{t}\right)$ at any particular temperature was plotted against the square root of time $(\sqrt{t})$ as shown in Figures 1, 2, and 3. The figures show initial increases in the mass of toluene sorbed until the maximum absorption was reached at which time, the mass of the absorbed toluene remained constant, that is, equilibrium absorption was attained. These figures show that at any particular temperature, the $75 / 25$ blend sorbed more toluene than the $50 / 50$ or $60 / 40 \mathrm{NR} / \mathrm{LLDPE}$ blend. The order in the amount of toluene sorbed $\left(Q_{t}\right)$ by the blends at the three temperatures studied is $75 / 25>50 / 50>60 / 40 \mathrm{NR} / \mathrm{LLDPE}$ blend.

3.1. Diffusion Coefficient (D). The diffusion coefficient of a solvent molecule through a polymer membrane can be obtained using Fickian's second law of diffusion [35]

$$
D=\pi\left(\frac{h \theta}{4 Q_{\infty}}\right)^{2}
$$

where $h$ is the blend thickness, $\theta$ is the slope of the initial linear portion of the plot of $Q_{t}$ against $\sqrt{t}$, and $Q_{\infty}$ is the equilibrium absorption. The $D$ values are given in Table 2 along with other sorption parameters. From Table 2 and for the NR/LLDPE blends 50/50 and 60/40, the diffusion coefficient $(D)$ was observed to increase with increases in the sorption temperature. However, for the 75/25 NR/LLDPE 


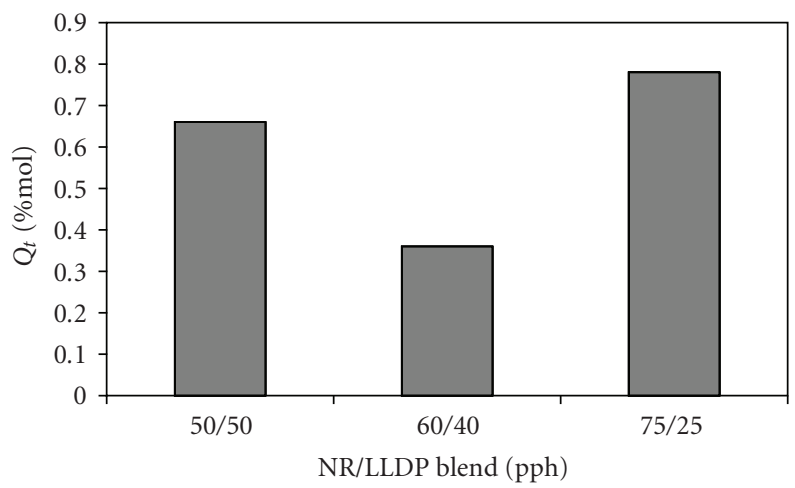

FIgURE 1: The variation of equilibrium toluene uptake $Q_{t}(\% \mathrm{~mol})$ of NR/LLDPE blend with blend composition of at $55^{\circ} \mathrm{C}$.

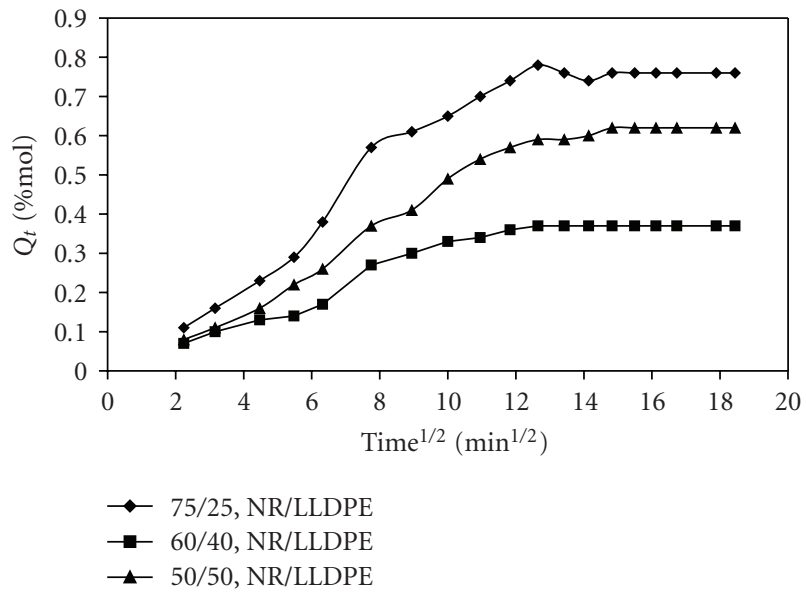

Figure 2: Plot of sorption data of NR/LLDPE blends at $35^{\circ} \mathrm{C}$.

blend, the diffusion coefficient was observed to decrease at $55^{\circ} \mathrm{C}$ but increased again at $65^{\circ} \mathrm{C}$. At the sorption temperatures of $35^{\circ} \mathrm{C}$ and $65^{\circ} \mathrm{C}$ investigated, the order of the diffusion coefficient of the blends (NR/LLDPE) is $75 / 25>$ $50 / 50>60 / 40$. However, at $55^{\circ} \mathrm{C}$, the order in the values of diffusion coefficient $(D)$ is $50 / 50>75 / 25>60 / 40$ NR/LLDPE. From this study, no dependence of diffusion coefficient $(D)$ on the amount of NR and LLDPE in the blends was observed.

3.2. Sorption Coefficient $(S)$. The sorption coefficient $(S)$ was calculated using.

$$
S=\frac{M_{\infty}}{M_{0}}
$$

where $M_{\infty}$ is the mass of toluene sorbed at equilibrium and $M_{0}$ is the initial mass of the blend. $M_{\infty}$ is given as

$$
\mathrm{M}_{\infty}=Z \times \text { molecular weight of toluene, }
$$

where $Z$ denotes moles of solvent sorbed at equilibrium swelling. The values of the sorption coefficient $(S)$ are also shown in Table 2. From Table 2, it is evident that the 75/25 NR/LLDPE blend has the highest value of $S$ at all the

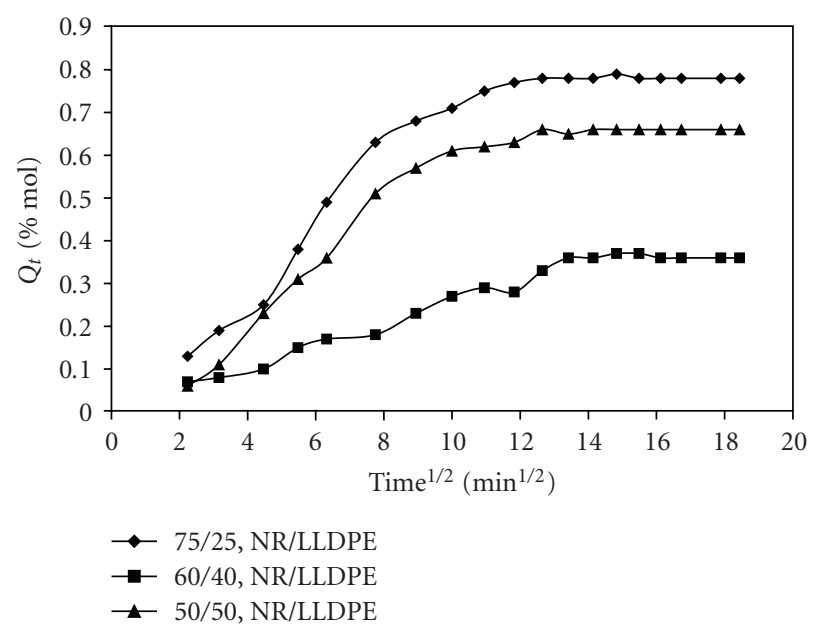

FIgure 3: Plot of sorption data of NR/LLDPE blends at $55^{\circ} \mathrm{C}$.

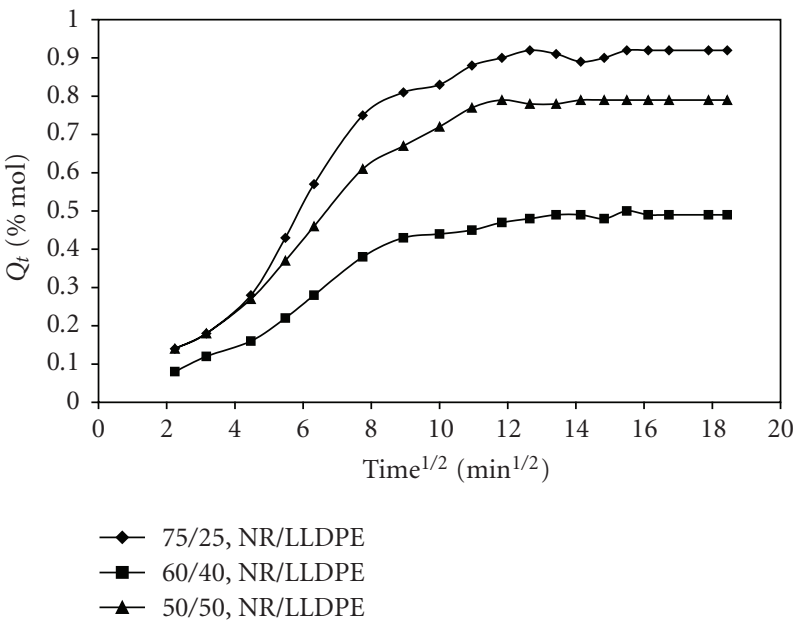

Figure 4: Plot of sorption data of NR/LLDPE blends at $65^{\circ} \mathrm{C}$.

temperatures investigated while the $60 / 40$ blend has the least value. The order in the variation of $S$ with temperature of investigations for the blends is $75 / 25>50 / 50>60 / 40$ NR/LLDPE. From Table 2, also it is clear that as the sorption temperature increased, the values of $S$ also increased for the blends 50/50 and 75/25 (NR/LLDPE). The 60/40 blend (NR/LLDPE) did not show any definite order of $S$ with the sorption temperature. This behaviour was also noted for the diffusion coefficient of the blend.

3.3. Permeability Coefficient $(P)$. The permeability coefficient $(P)$ of toluene in the rubber blends was obtained as follows [35]:

$$
P=D \cdot S,
$$

where $D$ is the diffusion coefficient and $S$ is the sorption coefficient. The values of $P$ are given in Table 2. The permeability coefficients of the blends $50 / 50$ and $60 / 40$ NR/LLDPE were observed to increase with increases in the sorption temperature, and followed the same trend as the 
TABLE 2: Sorption properties of rubber blends at different temperatures.

\begin{tabular}{lcccc}
\hline Temp ${ }^{\circ} \mathrm{C}$ & $\begin{array}{c}\text { Blend Composition } \\
\text { NR/LLDPE }\end{array}$ & $\begin{array}{c}\text { Diffusion Coefficient } \\
D\left(\mathrm{~cm}^{2} / \mathrm{min}\right)\end{array}$ & $\begin{array}{c}\text { Sorption } S(\%) \\
\left(\mathrm{cm}^{2} / \mathrm{min}^{2}\right)\end{array}$ \\
\hline \multirow{3}{*}{55} & $50 / 50$ & $9.52 \times 10^{-5}$ & $15.00 \times 10^{-2}$ & $14.30 \times 10^{-6}$ \\
& $60 / 40$ & $3.86 \times 10^{-5}$ & $10.30 \times 10^{-2}$ & $3.98 \times 10^{-6}$ \\
& $75 / 25$ & $24.50 \times 10^{-5}$ & $17.90 \times 10^{-2}$ & $43.90 \times 10^{-6}$ \\
\hline 55 & $50 / 50$ & $17.90 \times 10^{-5}$ & $16.90 \times 10^{-2}$ & $30.30 \times 10^{-6}$ \\
& $60 / 40$ & $4.20 \times 10^{-5}$ & $10.00 \times 10^{-2}$ & $4.20 \times 10^{-6}$ \\
& $75 / 25$ & $12.40 \times 10^{-5}$ & $18.40 \times 10^{-2}$ & $22.80 \times 10^{-6}$ \\
\hline & $50 / 50$ & $23.00 \times 10^{-5}$ & $20.20 \times 10^{-2}$ & $46.50 \times 10^{-6}$ \\
& $60 / 40$ & $7.78 \times 10^{-5}$ & $14.10 \times 10^{-2}$ & $11.00 \times 10^{-6}$ \\
& $75 / 25$ & $45.30 \times 10^{-5}$ & $22.90 \times 10^{-2}$ & $105.60 \times 10^{-6}$ \\
\hline
\end{tabular}

diffusion coefficient $(D)$. It may be inferred that the diffusion process controls the permeability. At the temperatures of 35 and $65^{\circ} \mathrm{C}$ studied, the observed order in the values of $P$ is $75 / 25>50 / 50>60 / 40$ while at $55^{\circ} \mathrm{C}$, the observed order is $50 / 50>75 / 25>60 / 40$. The 75/25 NR/LLDPE blend showed a decrease in permeability at $55^{\circ} \mathrm{C}$ and which later increased at $65^{\circ} \mathrm{C}$. This behaviour was also noted for the diffusion coefficient $(D)$ of this blend, that is, 75/25 NR/LLDPE blend.

\section{Transport Mechanism}

In order to study the mechanism of transport phenomenon, the sorption data have been fitted into the relation [36]

$$
\log \left(\frac{Q_{t}}{Q_{\infty}}\right)=\log k+n \log t
$$

where $Q_{t}$ is the swelling quotient at time $t$, and $Q_{\infty}$, the equilibrium swelling. $k$ is a constant which depends on the polymer morphology and the polymer-solvent interaction. The value of $n$ determines the mode of transport of toluene through the rubber blends. For a Fickian transport, $n=0.5$, When $n=1.0$, it indicates Case II (relaxation controlled) transport, and when $n$ lies between 0.5 and 1.0, it indicates anomalous transport behaviour. The values of $n$ and $k$ were obtained from the plot of $\log \left(Q_{t} / Q_{\infty}\right)$ against $\log t$ and are shown in Table 3.

Table 3 shows that with the exception of the 60/40 NR/LLDPE blend at 35 and $55^{\circ} \mathrm{C}$, the values of $n$ obtained for the different NR/LLDPE blends at different temperatures are non-Fickian and may be described as anomalous. At $55^{\circ} \mathrm{C}$, the transport of toluene through the 60/40 NR/LLDPE blend is best described as Fickian. The value of $n$ obtained for the $60 / 40 \mathrm{NR} / \mathrm{LLDPE}$ blend at $35^{\circ} \mathrm{C}$ is 0.4 , which indicates that the transport of toluene through the blend at $35^{\circ} \mathrm{C}$ is neither Fickian nor anomalous, and therefore may be regarded as pseudo-Fickian. The values of $k$ were observed to decrease with increases in sorption temperature for the blends 60/40 and $75 / 25$. For the 50/50 NR/LLDPE blend, the values of $k$ were found to decrease at $55^{\circ} \mathrm{C}$ but increased again at $65^{\circ} \mathrm{C}$. The $60 / 40 \mathrm{NR} / \mathrm{LLDPE}$ blend has the highest values of $k$ at all the temperatures studied. The order observed in the variation of $k$ with blend composition (NR/LLDPE) at 35 and $55^{\circ} \mathrm{C}$ is $60 / 40>75 / 25>50 / 50$. However, at $65^{\circ} \mathrm{C}$, the
TABle 3: Values of Equilibrium Toluene Uptake $Q_{t}(\mathrm{~mol} \%)$ and Parameters $n$ and $k$ for NR/LLDPE Blends at different Temperatures.

\begin{tabular}{ccccc}
\hline Temp ${ }^{\circ} \mathrm{C}$ & $\begin{array}{c}\text { Blend } \\
\text { composition } \\
\text { NR/LLDPE }\end{array}$ & $Q_{t}(\% \mathrm{~mol})$ & $n$ & $k$ \\
\hline \multirow{3}{*}{35} & $50 / 50$ & 0.620 & 0.6 & 0.0485 \\
& $60 / 40$ & 0.370 & 0.4 & 0.0952 \\
& $75 / 25$ & 0.260 & 0.6 & 0.0584 \\
\hline 55 & $50 / 50$ & 0.660 & 0.9 & 0.0247 \\
& $60 / 40$ & 0.360 & 0.5 & 0.0850 \\
& $75 / 25$ & 0.780 & 0.7 & 0.0535 \\
\hline \multirow{3}{*}{75} & $50 / 50$ & 0.790 & 0.7 & 0.0433 \\
& $60 / 40$ & 0.490 & 0.6 & 0.0610 \\
& $75 / 25$ & 0.920 & 0.8 & 0.0289 \\
\hline
\end{tabular}

observed order is $60 / 40>50 / 50>75 / 25$. The value of the constant $k$ obtained in this study for the rubber blends is an indication of the degree of rubber blend-toluene interaction.

4.1. Activation Parameters. The temperature dependence of transport properties was used to evaluate the activation energy for the diffusion, and permeation processes using the Arrhenius relation [37]

$$
\log X=\log X_{o}-\left(E_{x} / 2.303 \mathrm{RT}\right)
$$

where $\mathrm{X}$ represents either $D$ or $P, X_{\mathrm{O}}$ is a constant representing either $D_{\mathrm{O}}$ or $P_{\mathrm{O}}, E_{X}$ is either $E_{D}$ or $E_{P}$. Plots of $X$ against I/T were used to calculate the activation parameters of diffusion $\left(E_{D}\right)$ and permeation $\left(E_{P}\right)$. Values of $E_{D}$ and $E_{P}$ are presented in Table 4. From Table 4, it is seen that as the amount of LLDPE decreased in the blend, the values of $E_{D}$ and $E_{P}$ also decreased, and vice versa. Conversely, as the amount of NR increased in the blend, the values of $E_{D}$ and $E_{P}$ also decreased and vice versa. Generally, the direction of increase of $E_{D}$ and $E_{P}$ values indicates the direction of increasing solvent resistance of the blends, and vice versa. In essence therefore, and in agreement with our earlier observation on the molar percentage uptake $\left(Q_{t}\right)$ of toluene 
TAble 4: Values of Activation Energies of Diffusion $\left(E_{D}\right)$, Permeation $\left(E_{P}\right)$, and Heat of Solution $\left(\Delta H_{S}\right)$ for various NR/LLDPE Blends.

\begin{tabular}{lccc}
\hline $\begin{array}{l}\text { Blend composition } \\
\text { NR/LLDPE }\end{array}$ & $E_{D} \mathrm{KJ} / \mathrm{mol}$ & $E_{P} \mathrm{KJ} / \mathrm{mol}$ & $\Delta H_{S} \mathrm{KJ} / \mathrm{mol}$ \\
\hline $50 / 50$ & 25.45 & 33.38 & 7.93 \\
$60 / 40$ & 17.33 & 24.67 & 7.34 \\
$75 / 25$ & 10.24 & 18.82 & 8.58 \\
\hline
\end{tabular}

by different blend compositions, the $75 / 25$ blend is least resistant to toluene sorption.

The heat of sorption, $\Delta H_{S}$, was calculated using the relation

$$
\Delta H_{S}=E_{P}-E_{D}
$$

The values of $\Delta H_{S}$ obtained are included in Table 4. The order in the variation of $\Delta H_{S}$ with blend composition is $75 / 25>50 / 50>60 / 40 \mathrm{NR} / \mathrm{LLDPE}$. The variation of $\Delta H_{S}$ with blend compositions was within \pm 2.0 . The positive $\Delta H_{S}$ values obtained in this study for the blends suggests that sorption in this study is dominated by Henry's type sorption with an endothermic contribution.

\section{Conclusions}

The diffusion of toluene through natural rubber/linear low density polyethylene blends has been studied. The 75/25 NR/LLDPE blend that contains with the highest amount of natural rubber exhibited the highest amount of molar percentage uptake $\left(Q_{t}\right)$ of toluene at the temperatures studied. The diffusion coefficient $(D)$ and permeation $(P)$ obtained for toluene in the 50/50 and 60/40 natural rubber/linear low density polyethylene blends were found to increase with an increase in the sorption temperature. For the 75/25 NR/LLDPE blend, the diffusion coefficient and permeation were found to decrease at $55^{\circ} \mathrm{C}$ but increased again at $65^{\circ} \mathrm{C}$. The sorption coefficient $(S)$ for the rubber blends was found to increase with an increase in the sorption temperature. The transport of toluene through the 60/40 NR/LLDPE blend was found to be Fickian at $55^{\circ} \mathrm{C}$, pseudo-Fickian at $35^{\circ} \mathrm{C}$, while for the other blends at the three temperatures studies, it is anomalous. The calculated activation energies of diffusion and permeation in the rubber blends were all positive and were found to decrease with an increase in the amount of natural rubber or decreases in the amount of LLDPE in the blends. The calculated heat of sorption for the blends was all positive, and its variation among the difference rubber blends was within \pm 2.0 .

\section{References}

[1] J. Crank, The Mathematics of Diffusion, Clarendon Press, Oxford, UK, 2nd edition, 1975.

[2] K. E. George, in Blends and Alloys, Chapman and Hall, London, UK, 1st edition, 1993.
[3] M. W. Walters and D. N. Keyte, "Heterogeneous structure in blends of rubber polymers," Rubber Chemistry and Technology, vol. 38, p. 62, 1965.

[4] L. N. Valsamis, M. R. Kear, R. Joseph, and D. Francis, "Specificenzyme release of cellulose-bound drugs, experimental and theoretical study," Journal of Applied Polymer Science, vol. 32, no. 1, pp. 2851-3348, 1986.

[5] L. N. Valsamis, M. R. Kearney, S. S. Dagli, D. D. Merhta, and A. P. Polchocki, "Phase morphology of a model polyblend fabricated in industrial mixers: time and melt flow dependent supradomain structures," Advances in Polymer Technology, vol. 8, no. 2, pp. 115-130, 1988.

[6] J. Li, R. A. Shanks, and Y. Long, "Mechanical properties and morphology of polyethylene-polypropylene blends with controlled thermal history," Journal of Applied Polymer Science, vol. 76, no. 7, pp. 1151-1164, 2000.

[7] Z. Yao, Z. Yin, G. Sun, et al., "Morphology, thermal behavior, and mechanical properties of PA6/UHMWPE blends with HDPE-g-MAH as a compatibilizing agent," Journal of Applied Polymer Science, vol. 75, no. 2, pp. 232-238, 2000.

[8] S. N. Sathe, S. Devi, and K. V. Rao, "Relationship between morphology and mechanical properties of binary and compatibilized ternary blends of polypropylene and nylon 6," Journal of Applied Polymer Science, vol. 61, no. 1, pp. 97-107, 1996.

[9] W. Yang, Q. Wu, L. Zhon, and S. Wang, "Styrene-coacrylonitrile resin modifications of PVC/CPE blends," Journal of Applied Polymer Science, vol. 66, no. 8, pp. 1455-1460, 1997.

[10] S. N. Koklas, D. D. Sotiropoulou, J. K. Kallitsis, and K. Kalfoglou, "Compatibilization of chlorinated polyethylene/poly(vinyl chloride) blends with epoxidized natural rubber," Polymer, vol. 32, no. 1, pp. 66-72, 1991.

[11] N. Kukaleva, M. Jollands, F. Cser, and E. Kosior, "Influence of phase structure on impact toughening of isotactic polypropylene by metallocene-catalyzed linear low-density polyethylene," Journal of Applied Polymer Science, vol. 76, no. 7, pp. 1011-1018, 2000.

[12] B. Ohlsson, H. Hassander, and B. Tornell, "Effect of the mixing procedure on the morphology and properties of compatibilized polypropylene/polyamide blends," Polymer, vol. 39, no. 20, pp. 4715-4721, 1998.

[13] D. R. Paul, Ed., Polymer Blends, vol. 11, chapter 12, Academic Press, New York, NY, USA, 1976.

[14] Y. M. Lee, D. Bourgeois, and G. Belfort, "Sorption, diffusion, and pervaporation of organics in polymer membranes," The Journal of Membrane Science, vol. 44, no. 2-3, pp. 161-181, 1989.

[15] R. V. Rao and M. Yassen, "Effect of temperature on rates of permeation of chloride ions and water vapour through alkyd coatings ," Pigment \& Resin Technology, vol. 7, no. 2, pp. 4-8, 1978.

[16] R. T. Ruggeri and T. R. Beck, "An investigation of the mass transfer characteristics of polyurethane paint," Organic Coatings and Plastics Chemistry, vol. 43, pp. 580-585, 1980.

[17] J. Koszinowoski, "Diffusion and solubility of $n$-alkanes in polyolefines," Journal of Applied Polymer Science, vol. 32, no. 5, pp. 4765-4786, 1986.

[18] A. R. Berens and H. B. Hopfenberg, "Diffusion of organic vapors at low concentrations in glassy PVC, polystyrene, and PMMA," Journal of Membrane Science, vol. 10, no. 2-3, pp. 283-303, 1982.

[19] S. T. Hwang, C. K. Choi, and K. Kammermeyer, "Gaseous transfer coefficients in membranes," Journal of Separation Science, vol. 9, no. 6, pp. 461-478, 1974. 
[20] J. R. Robinson, Sustained and Controlled Release of Drug Delivery Systems, Marcel Dekker, New York, NY, USA, 1978.

[21] H. B. Hopffenberg and D. R. Paul, Transport Phenomena, Polymer Blends, vol. 1, Academic Press, New York, NY, USA, 1978.

[22] A. T. Koshy, B. Kuriakose, and S. Thomas, "Studies on the effect of blend ratio and cure system on the degradation of natural rubber-ethylene-vinyl acetate rubber blends," Polymer Degradation and Stability, vol. 36, no. 2, pp. 137-147, 1992.

[23] A. T. Koshy, B. Kuriakose, S. Thomas, and S. Varghese, "Studies on the effect of blend ratio and crosslinking system on thermal, X-ray and dynamic mechanical properties of blends of natural rubber and ethylene-vinyl acetate copolymer," Polymer, vol. 34, no. 16, pp. 3428-3436, 1993.

[24] A. T. Koshy, B. Kuriakose, S. Thomas, and S. Varghese, "Viscoelastic properties of silica-filled natural rubber and ethylene-vinyl acetate copolymer blend," Polymer-Plastics Technology and Engineering, vol. 33, no. 2, pp. 149-159, 1994.

[25] P. Jansen and B. G. Soares, "Effect of compatibilizer and curing system on the thermal degradation of natural rubber/EVA copolymer blends," Polymer Degradation and Stability, vol. 52, no. 1, pp. 95-99, 1996.

[26] P. Jansen, A. S. Gomes, and B. G. Soares, "The use of EVAcontaining mercapto groups in natural rubber-EVA blends. II. The effect of curing system on mechanical and thermal properties of the blends," Journal of Applied Polymer Science, vol. 61, no. 4, pp. 591-598, 1996.

[27] T. Johnson and S. Thomas, "Natural rubber/epoxidised natural rubber-25 blends: morphology, transport phenomena and mechanical properties," Journal of Materials Science, vol. 34, no. 13, pp. 3221-3239, 1999.

[28] R. Asaletha, M. G. Kumaran, and S. Thomas, "Transport behaviour of aliphatic hydrocarbons through dynamically crosslinked natural rubber/polystyrene blends," Polymers and Polymer Composites, vol. 6, no. 6, pp. 357-371, 1998.

[29] S. George, K. T. Varughese, and S. Thomas, "Molecular transport of aromatic solvents in isotactic polypropylene/ acrylonitrile-co-butadiene rubber blends," Polymer, vol. 41, no. 2, pp. 579-594, 2000.

[30] S. C. George, G. Groeninckx, K. N. Ninan, and S. Thomas, "Molecular transport of aromatic hydrocarbons through nylon-6/ethylene propylene rubber blends: relationship between phase morphology and transport characteristics," Journal of Polymer Science, vol. 38, no. 16, pp. 2136-2153, 2000.

[31] V. Tanrattanakul and W. Udomkichdecha, "Development of novel elastomeric blends containing natural rubber and ultralow-density polyethylene," Journal of Applied Polymer Science, vol. 82, no. 3, pp. 650-660, 2001.

[32] A. Ahmad, D. H. Mohd, and I. Abdullah, "Mechanical properties of filled NR/LLDPE blends," Iranian Polymer Journal, vol. 13, no. 3, pp. 173-178, 2004.

[33] G. Unnikrishnan and S. Thomas, "Diffusion and transport of aromatic hydrocarbons through natural rubber," Polymer, vol. 35, no. 25, pp. 5504-5510, 1994.

[34] P. Danwanichakul, S. Jaroenkarn, P. Jumpathi, and D. Dechojarassri, "Sorption and desorption of toluene, m-xylene, pcresol and water by natural rubber chips," Songklanakarin Journal of Science and Technology, vol. 28, no. 5, pp. 10711082, 2006.

[35] J. Crank, The Mathematics of Diffusion, Oxford Clarendon Press, Oxford, UK, 2nd edition, 1975.
[36] L. M. Lutch and N. A. Peppas, "Transport of penetrants in the macromolecular structure of coals. V. Anomalous transport in pretreated coal particles," Journal of Applied Polymer Science, vol. 33, no. 5, pp. 1557-1566, 1987.

[37] A. E. Mathai and S. Thomas, "Transport of aromatic hydrocarbons through cross-linked nitrile rubber membranes," Journal of Macromolecular Science Part B, vol. 35, no. 2, 229 pages, 1996. 

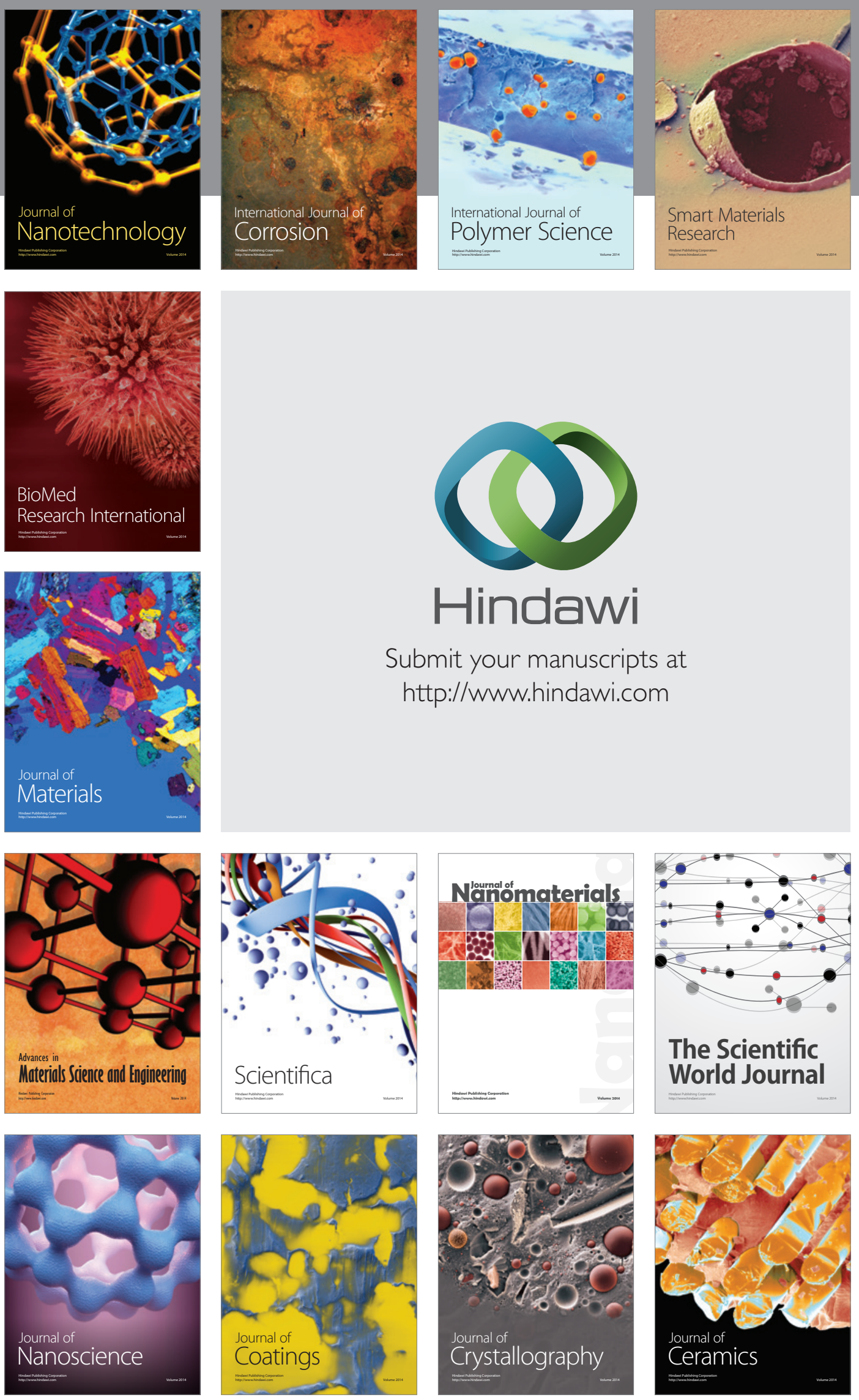

The Scientific World Journal

Submit your manuscripts at

http://www.hindawi.com

\section{World Journal}

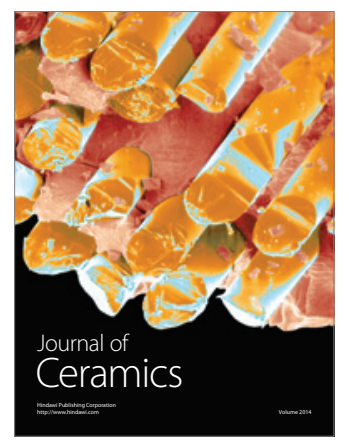

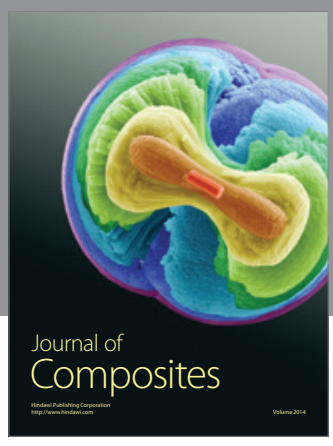
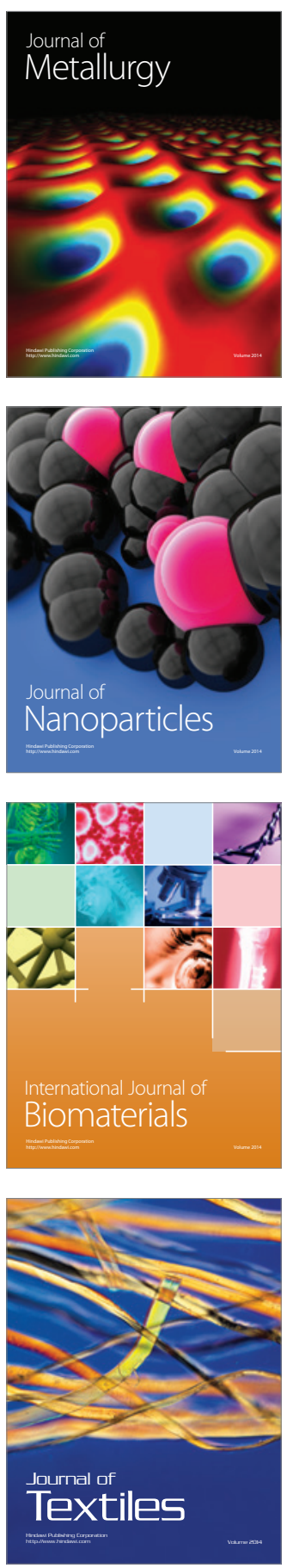